\title{
The First Description of Monozygotic Twin Females Discordant for the Craniofrontonasal Syndrome Phenotype and the Report of Four Novel Pathogenic Variants in the EFNB1 Gene
}

Ewelina Bukowska-Olech ( $\sim$ ewe.olech@gmail.com )

Uniwersytet Medyczny imienia Karola Marcinkowskiego w Poznaniu https://orcid.org/0000-0003-0509-1696

\section{Paweł Gawliński}

Department of Medical Genetics, Institute of Mother and Child, Warsaw

Anna Jakubiuk-Tomaszuk

Department of Pediatric Neurology and Rehabilitation, Medical University of Białystok; Medical Genetics Unit, Mastermed Medical Center, Białystok

Maria Jędrzejowska

Children's Health Ireland at Crumlin Department of Clinical Genetics

\section{Ewa Obersztyn}

Department of Medical Genetics, The Children's Memorial Health Institute, Warsaw

\section{Michał Piechota}

Centrers for Medical Genetics GENESIS, Poznań

\section{Marta Bielska}

Departemnt of Pediatrics, Hematology, Oncology and Diabetology, Medical University of Łódź, Łódź

\section{Aleksander Jamsheer}

Uniwersytet Medyczny im Karola Marcinkowskiego w Poznaniu: Uniwersytet Medyczny imienia Karola Marcinkowskiego w Poznaniu

\section{Research}

Keywords: monozygosity, discordant phenotype, EFNB1, ephrin B1, coronal craniosynostosis, custom targeted next-generation sequencing

Posted Date: April 6th, 2021

DOl: https://doi.org/10.21203/rs.3.rs-386853/v1

License: (c) (1) This work is licensed under a Creative Commons Attribution 4.0 International License. Read Full License 


\section{Abstract}

Background: Craniofrontonasal syndrome (CFNS) is a rare X-linked disorder that results from pathogenic variants in the EFNB1 gene. The syndrome paradoxically presents with greater severity of the symptoms in heterozygous females than hemizygous males.

Results: Our primary finding was the description of monozygotic twins, i.e., patients $5 \& 6$, discordant for the CFNS phenotype. Intriguingly, patient 5 presented classical CFNS gestalt, whereas patient 6 manifested only very subtle craniofacial features, not resembling CFNS. Besides, we have expanded the mutational spectrum of the EFNB1 gene through reporting four novel pathogenic variants - p.(Trp12*), p.(Cys64Phe), p.(Tyr73Metfs*86), p. (Glu210*). All those alterations were found applying either targeted NGS of a custom gene panel or PCR followed by Sanger sequencing and evaluated using in silico predictors. Lastly, we have also expanded the CFNS phenotypic spectrum by describing in patient 3 novel features of the syndrome, such as bifid hallux, bicornuate uterus, and abnormal right ovary segmented into six parts

Conclusions: We have described the unreported so far differences of the clinical phenotype in the monozygotic twin patients $5 \& 6$ harbouring an identical p.(Glu210*) variant located in the EFNB1 gene. With our finding, we have pointed to an unusual phenomenon of mildly affected females with CFNS, who may not manifest features suggestive of the syndrome. Consequently, this study may be valuable for geneticists consulting patients with craniofacial disorders.

\section{Introduction}

Craniofrontonasal syndrome (CFNS; MIM: 304110) is a rare X-linked disorder that inherits in a paradoxical manner, exceptionally presenting greater severity of symptoms in heterozygous females than hemizygous males $(1,2)$. The clinical picture in the affected females encompasses coronal craniosynostosis (CS), frontal bossing, hypertelorism, depressed nasal bridge, bifid nose, craniofacial asymmetry, downslanting palpebral fissures, frizzy and curly hair, syndactyly and longitudinally ridged fingernails. Intriguingly, many symptomatic hemizygous men show merely hypertelorism with no other congenital anomalies of major facial dysmorphism $(3,4)$.

Wieacker and Wieland in 2005 explained the above paradox as a cellular interference, which assumes that due to a random $X$-inactivation, heterozygous females are uniquely mosaic and therefore have both functional and nonfunctional ephrin-B1, a protein which is encoded by the EFNB1 gene (Wieland et al., 2004; Wieacker and Wieland, 2005). These two ephrin-B1 forms' coexistence affects the adhesion and sorting of cells, disrupting normal embryological development $(6,7)$. Further reports describing more severely affected males, who all were mosaic for deleterious variants in the EFNB1, strengthen the hypothesis about the described pathomechanism's biological relevance (8). However, the precise molecular explanation for this phenomenon remains not yet fully understood (7).

\section{Cohort description}

We recruited four sporadic female individuals (patients 1-4) and one familial case consisting of two female individuals (patient $5 \& 6$ ), out of whom all but one, i.e. patient 6 , presented phenotypic features suggestive of CFNS. 


\section{Results}

\section{Clinical report}

We recruited six female cases who, out of whom all but one, i.e. patient 6 , presented with phenotypic characteristics suggestive for CFNS. The comparison of all clinical features noted in our cohort was outlined in Table 1, whereas the photographic documentation of facial dysmorphism and hand and foot anomalies was shown in Supplementary Fig. 1. Our study's primary finding was the description of monozygotic twins, i.e., patients $5 \& 6$, discordant for the CFNS phenotype. Patient 5 presented with classical CFNS dysmorphia such as corse facial feature, CS and syndactyly (Fig. 1a-d), whereas patient 6 manifested only very subtle craniofacial features not resembling CFNS (Fig. 1e). 
Table 1

Clinical manifestations of seven patients with craniofrontonasal syndrome. ID - intellectual disability HPO no. Human Phenotype Ontology database number identification for phenotypic abnormality (Köhler et al., 2014); Symbols: +, feature present; (+); -, feature absent; nd, no data; na, not applicable.

\begin{tabular}{|c|c|c|c|c|c|c|c|c|}
\hline \# & Features & HPO no. & patient 1 & $\begin{array}{l}\text { patient } \\
2\end{array}$ & patient 3 & $\begin{array}{l}\text { patient } \\
4\end{array}$ & $\begin{array}{l}\text { patient } \\
5\end{array}$ & $\begin{array}{l}\text { patient } \\
6\end{array}$ \\
\hline 1 & $\begin{array}{l}\text { Variant: } \\
\text { NM_004429.4 }\end{array}$ & & c. $35 \mathrm{G}>\mathrm{A}$ & $\begin{array}{l}\text { c. } 191 \mathrm{G} \\
>\mathrm{T}\end{array}$ & c.216del & $\begin{array}{l}\text { c. } 451 \mathrm{G} \\
>\mathrm{A}\end{array}$ & $\begin{array}{l}\text { c. } 628 \mathrm{G} \\
>T\end{array}$ & $\begin{array}{l}\text { c. } 628 \mathrm{G} \\
>\mathrm{T}\end{array}$ \\
\hline 2 & Sex & & $\mathrm{F}$ & $\mathrm{F}$ & $\mathrm{F}$ & $\mathrm{F}$ & $\mathrm{F}$ & $\mathrm{F}$ \\
\hline 3 & Relationship & & na & na & na & na & Twin 1 & Twin 2 \\
\hline 4 & Hypertelorism & HP:0000316 & + & + & + & + & + & - \\
\hline 5 & Epicanthus & HP:0000286 & - & + & + & - & + & - \\
\hline 6 & $\begin{array}{l}\text { Down-slanting } \\
\text { palpebral } \\
\text { fissures }\end{array}$ & HP:0000494 & $\begin{array}{l}\text { Up- } \\
\text { slanting } \\
\text { palpebral } \\
\text { fissures }\end{array}$ & - & $\begin{array}{l}\text { up- } \\
\text { slanting } \\
\text { palpebral } \\
\text { fissures }\end{array}$ & + & - & - \\
\hline 7 & Anteverted nares & HP:0000463 & + & + & + & + & + & + \\
\hline 8 & $\begin{array}{l}\text { Depressed nasal } \\
\text { bridge }\end{array}$ & HP:0005280 & + & + & $\begin{array}{l}\text { prominent } \\
\text { nasal } \\
\text { bridge }\end{array}$ & + & + & + \\
\hline 9 & $\begin{array}{l}\text { Midline nasal } \\
\text { groove }\end{array}$ & HP:0004112 & + & & + & + & + & - \\
\hline 10 & $\begin{array}{l}\text { Abnormality of } \\
\text { the pinna }\end{array}$ & HP:0000377 & $\begin{array}{l}+ \text { thick } \\
\text { helix }\end{array}$ & - & $\begin{array}{l}\text { prominent } \\
\text { antihelix }\end{array}$ & + & + & - \\
\hline 11 & Low-set ears & HP:0000369 & - & + & + & + & + & + \\
\hline 12 & $\begin{array}{l}\text { Coarse facial } \\
\text { feature }\end{array}$ & HP:0000280 & + & + & + & + & + & + \\
\hline 13 & $\begin{array}{l}\text { Midface } \\
\text { retrusion }\end{array}$ & HP:0011800 & + & + & + & + & - & - \\
\hline 14 & Micrognathia & HP:0000347 & + & - & - & + & + & + \\
\hline 15 & High palate & HP:0000218 & + & + & + & + & - & - \\
\hline 16 & $\begin{array}{l}\text { Anterior open } \\
\text { bite }\end{array}$ & HP:0200095 & + & + & + & + & - & - \\
\hline 17 & Cleft upper lip & HP:0000204 & - & - & - & - & - & - \\
\hline 18 & $\begin{array}{l}\text { Bilateral cleft lip } \\
\text { and palate }\end{array}$ & HP:0002744 & - & - & - & - & - & - \\
\hline 19 & Ankyloglossia & HP:0010296 & - & $?$ & + & - & - & - \\
\hline 20 & Hoarse voice & HP:0001609 & - & $?$ & + & - & * & * \\
\hline 21 & Short neck & HP:0000470 & + & + & + & + & - & + \\
\hline
\end{tabular}




\begin{tabular}{|c|c|c|c|c|c|c|c|c|}
\hline \# & Features & HPO no. & patient 1 & patient & patient 3 & patient & $\begin{array}{l}\text { patient } \\
5\end{array}$ & patient \\
\hline 22 & $\begin{array}{l}\text { Small anterior } \\
\text { fontanelle }\end{array}$ & HP:0000237 & - & $?$ & $?$ & $?$ & - & - \\
\hline 23 & $\begin{array}{l}\text { Dysgenesis of } \\
\text { the corpus } \\
\text { callosum }\end{array}$ & HP:0006989 & $?$ & & $\begin{array}{l}+ \\
\text { (posterior } \\
\text { part) }\end{array}$ & - & $?$ & $?$ \\
\hline 24 & $\begin{array}{l}\text { Agenesis of the } \\
\text { corpus callosum }\end{array}$ & HP:0001274 & $?$ & + & - & + & $?$ & $?$ \\
\hline 25 & Plagiocephaly & HP:0001357 & - & + & - & + & + & - \\
\hline 26 & Craniosynostosis & HP:0001363 & - & + & + & + & + & - \\
\hline 27 & $\begin{array}{l}\text { Global } \\
\text { developmental } \\
\text { delay }\end{array}$ & HP:0001263 & $\begin{array}{l}+ \\
\text { Mild ID }\end{array}$ & - & $\begin{array}{l}+ \\
\text { Mild ID }\end{array}$ & + & - & - \\
\hline 28 & Brachydactyly & HP:0001156 & + & - & + & - & + & + \\
\hline 29 & Broad thumb & HP:0011304 & + & - & $\begin{array}{l}\text { duplicated } \\
\text { thumb }\end{array}$ & - & + & - \\
\hline \multirow[t]{2}{*}{30} & Toe syndactyly & HP:0001770 & - & $+($ feet $)$ & - & - & + (feet) & - \\
\hline & $\begin{array}{l}\text { Finger } \\
\text { syndactyly }\end{array}$ & HP:0006101 & & & & & & \\
\hline 31 & $\begin{array}{l}\text { Longitudinal } \\
\text { ridging of } \\
\text { toenails }\end{array}$ & HP:0001807 & + & + & + & $?$ & + & + \\
\hline 32 & $\begin{array}{l}\text { Longitudinal } \\
\text { ridging of } \\
\text { fingernails }\end{array}$ & HP:0001807 & + & + & + & + & + & + \\
\hline 33 & $\begin{array}{l}\text { Shoulder girdle } \\
\text { muscle atrophy }\end{array}$ & HP:0003724 & - & + & + & $?$ & * & * \\
\hline 34 & $\begin{array}{l}\text { Limited shoulder } \\
\text { movement }\end{array}$ & HP:0006467 & - & $?$ & + & - & * & * \\
\hline 35 & Low-set nipples & HP:0002562 & + & + & + & - & - & - \\
\hline
\end{tabular}

Patient 3 presented some novel for CFNS clinical features such as a bifid hallux (Supplementary Fig. 1d) bicornuate uterus, abnormal right ovary segmented into six parts by five serpentine-like constrictions, with the largest ovary part of $1.5 \mathrm{~cm}$, while the smallest one of $0.5 \mathrm{~cm}$ in diameter. To our best knowledge, this phenotype has not been reported in CFNS yet. She also showed congenital horizontal nystagmus, alternating divergent strabismus, defects of the genitourinary system, including horseshoe kidney, and not noted in CFNS thus far.

\section{Patient 5}


Patient 5 was a girl born in the $38^{\text {th }}$ week of gestation from $4^{\text {th }}$ pregnancy twined to unrelated healthy parents (Figure 1f). The pregnancy history was unknown because patient 5 was adopted. Her body mass was $2370 \mathrm{~g}$ $\left(<3^{\text {rd }}\right.$ percentile), length $49 \mathrm{~cm}\left(<3^{\text {rd }}\right.$ percentile), Apgar score was 8-10-10 at $1^{\prime}, 3^{\prime}$ and $5^{\prime}$. She was referred for dysmorphic evaluation at $1^{\text {st }}$ month of age. She had a coarse face, plagiocephaly, CS, micrognathia, a small anterior fontanel, significant hypertelorism, bilateral epicanthal folds, bilateral low-set ears, flat nasal bridge, anteverted nares, and a midline crease of the nasal tip. Brachydactyly, syndactyly of toes and longitudinal ridging of a finger- and toenails were also observed. On examination at the age of 5.5 months, she presented with a weight of $6110 \mathrm{~g}\left(<3^{\text {rd }}\right.$ centile) and head circumference of $37.8 \mathrm{~cm}\left(<3^{\text {rd }}\right.$ centile).

\section{Patient 6}

Patient 6 was a girl born in the $38^{\text {th }}$ week of gestation from $4^{\text {th }}$ pregnancy twined to unrelated healthy parents (Figure 1f). The pregnancy history was unknown because patient 6 was adopted. Her body mass was $2330 \mathrm{~g}$ $\left(<3^{\text {rd }}\right.$ percentile), length $50 \mathrm{~cm}\left(<3^{\text {rd }}\right.$ percentile), Apgar score was 8-8-9 at 1', $3^{\prime}, 5^{\prime}$ and 10 '. She was referred for dysmorphic evaluation at $4^{\text {th }}$ month of age since her twin sister obtained a diagnosis of CFND. She had coarse facial features, anteverted nares, depressed nasal bridge, short neck and longitudinal ridging of a finger- and toenails.

\section{Targeted next-generation sequencing (NGS) and Sanger sequencing}

gDNA (isolated from peripheral blood lymphocytes) of Patients $1 \& 5$ was subject to targeted NGS of a custom gene panel that revealed two novel heterozygous variants in the EFNB1 gene - c.35G>A p.(Trp12*) and c.628G>T p.(Glu210*), respectively (Figure $2 a)$. The presence of both alterations was confirmed by Sanger sequencing. Patients 2-4 were screened before the advent of the NGS method. Thus the molecular diagnosis was achieved by Sanger sequencing on gDNA isolated from peripheral blood lymphocytes, which revealed the presence of the following three heterozygous alterations out of which two were novel - c.191G>T p.(Cys64Phe), c.216del p. (Tyr73Met $\left.f s^{\star} 86\right)$. In contrast, one variant has been previously reported c.451G>A p.(Gly151Ser) (HGMD no: CM041297) (Figure 2b). The family history of patient 5 showed that she has a twin sister who, despite the lack of typical CFNS symptoms, underwent targeted PCR and Sanger sequencing. We evaluated the pathogenicity of missense variants in silico applying multiple online prediction tools including Polyphen-2, SIFT, CADD, MutationTaster and other resources such as DANN, FATHMM-MKL, LRT, BayesDel addAF, BayesDel noAF, GERP, PhyloP100, PhastCons integrated into either VarSome online tool or Alamut ${ }^{\circledR}$ Visual software product. The classification of all variants was performed following the American College of Medical Genetics and Genomics (ACMG) guidelines (Table 2). Applying SWISS-MODEL, we have visualized in 3D both wild type and mutated missense alterations in the ephrin-B1, i.e. p.(Cys64Phe) and p.(Gly151Ser) (13). 
Table 2

The overview of missense and nonsense variants found in the EFNB1 gene through MutationTaster, Varsome online tools (obtained on $2^{\text {th }}$ November 2020) and Alamut ${ }^{\circledR}$ Visual software (obtained on $10^{\text {th }}$ November 2020)

\begin{tabular}{|c|c|c|c|c|}
\hline & patient 1 & patient 2 & patient 4 & patient $5 \& 6$ \\
\hline $\begin{array}{l}\text { coding DNA level } \\
\left(\mathrm{NM} \_004429.4\right)\end{array}$ & c. $35 \mathrm{G}>\mathrm{A}$ & c. $191 \mathrm{G}>\mathrm{T}$ & c. $451 \mathrm{G}>\mathrm{A}$ & c. $628 \mathrm{G}>\mathrm{T}$ \\
\hline gDNA level & g.815G>A & g.9683 & g.10712 & g.11092 \\
\hline $\begin{array}{l}\text { chromosomal } \\
\text { level (GRCh38) }\end{array}$ & chrX:68829811G>A & chrX:68838679G>T & chrX:68839708G>A & chrX:68840088G>T \\
\hline $\begin{array}{l}\text { Protein level NM } \\
\text { (NP_ }\end{array}$ & p.Trp12Ter & p.Cys64Phe & p.Gly151Ser & p.Glu210Ter \\
\hline Exon & 1 & 2 & 3 & 4 \\
\hline $\begin{array}{l}\text { HGMD (v15.11) } \\
\text { no. }\end{array}$ & Not reported & Not reported & CM041297 & Not reported \\
\hline dbSNP rs number & rs1482772814 & Not reported & rs28936069 & Not reported \\
\hline gnomAD (v2.1.1) & Not reported & Not reported & Not reported & Not reported \\
\hline 1000 Genomes & Not reported & Not reported & Not reported & Not reported \\
\hline $\begin{array}{l}\text { ACMG } \\
\text { classification }\end{array}$ & Pathogenic & Likely pathogenic & Likely pathogenic & Pathogenic \\
\hline SIFT (v6.2.0) & n.d. & Deleterious & Deleterious & n.d. \\
\hline PolyPhen-2 (v2) & n.d. & $\begin{array}{l}\text { Probably } \\
\text { damaging }\end{array}$ & $\begin{array}{l}\text { Probably } \\
\text { damaging }\end{array}$ & n.d. \\
\hline DANN (v2014) & 0.9954 & 0.9935 & 0.9989 & 0.9969 \\
\hline $\begin{array}{l}\text { FATHMM-MKL } \\
\text { (dbNSFP v4.1) }\end{array}$ & Damaging & Damaging & Damaging & Damaging \\
\hline $\begin{array}{l}\text { LRT (dbNSFP } \\
\text { v4.1) }\end{array}$ & Neutral & Deleterious & Deleterious & Neutral \\
\hline $\begin{array}{l}\text { BayesDel addAF } \\
\text { (v4.1) }\end{array}$ & Damaging & Damaging & Damaging & Damaging \\
\hline $\begin{array}{l}\text { BayesDel noAF } \\
\text { (v4.1) }\end{array}$ & Damaging & Damaging & Damaging & Damaging \\
\hline $\begin{array}{l}\text { MutationTaster } \\
\text { (v2013) }\end{array}$ & Disease causing & Disease causing & Disease causing & Disease causing \\
\hline
\end{tabular}

\section{Zygosity analysis}

The monozigosity of twin patient $5 \& 6$ was confirmed based on an analysis of 33 STR markers localized on 13, $18,21, X$ and $Y$ chromosomes. 


\section{$\mathrm{X}$ chromosome inactivation $(\mathrm{XCl})$ assay}

We detected random $\mathrm{XCl}$ in twin patient 6 (46\% vs. 54\%), who manifested facial features unsuggestive for CFNS, whereas non-random XCl (84\% vs. $16 \%)$ in twin patient 5, who showed a classical CFNS facial phenotype.

\section{Face2Gene analysis}

The craniofacial phenotype of patient 6 was assessed using Face2Gene online available tool. Among the suggested 30 different syndromes, CFNS was not listed by the algorithm. However, the first five proposed diagnoses were as follows - Cornelia de Lange syndrome, Costello syndrome, Megalencephaly-Capillary Malformation-Polymicrogyria Syndrome, Alpha-Thalassemia/mental Retardation Syndrome and CHARGE syndrome. On the contrary, the phenotype of patient 5 was correctly identified as CFNS (listed as second).

\section{Discussion}

Although monozygotic twins originate from a single zygote and share the same genetic material and similar intrauterine environment, they occasionally may show discordant phenotypes of monozygotic disorder. The differences in clinical phenotype can be explained through at least several mechanisms such as epigenetic factors, an asymmetric split of the embryo, discordant cell differentiation or abnormalities in placental blood flow (14-16). Surprisingly, here we have diagnosed monozygotic twin patients, i. e. patient $5 \& 6$, who presented with highly variable severity of the CFNS symptoms. Both individuals carried the same p.(Glu210*) pathogenic EFNB1 variant and identical germline genetic information. In patient 5, we noted a typical female presentation of CFNS (Table 1, Fig. 1a-d). In contrast, in patient 6, we only detected mild facial anomalies unsuggestive for CFNS, including anteverted nares, depressed nasal bridge, low-set ears, coarse facial features, micrognathia and short neck (Table 1 and Fig. 1e). Besides, the craniofacial phenotype of patient 6 was analyzed using Face2Gene, which did not match CFNS among the possible dysmorphological diagnoses.

Mild clinical features in female individuals with CFNS are rather unusual. As mentioned before, CFNS inherits paradoxically and presents more severe clinical symptoms in females, who harbour the heterozygous EFNB1 variants in comparison to hemizygous males. Furthermore, rarely reported mosaic male individuals are more severely affected than their hemizygous counterparts. This is because other ephrin family members can presumably substitute the complete lack of ephrin-B1 in purely hemizygous males $(3,7,17)$. In the medical literature, we have found merely one description of mildly affected CFNS female patient. Twigg et al. reported a familial case (family no. 3217) heterozygous for a missense pathogenic variant p.(Pro54Leu), in which one of the affected females had minimal clinical manifestations of CFNS. However, this patient was shown to have a lower mutation level in the hair roots and buccal swab (2). In our case, we were unable to check for the mosaicism in mesoderm or ectoderm-derived cell lines, although the level for the causative variant in blood cells reached $50 \%$ of reads, being unsuggestive of somatic mosaicism.

Except for mosaicism in other than blood cells, one may suspect the presence of additional modifiers of the phenotype, including epigenetic factors (18-20). To check whether the variable severity of CFNS in both twin females resulted from skewed $\mathrm{X}$ chromosome inactivation, we performed $\mathrm{XCl}$ testing. We hypothesized that similar to male patients who show minimal CFNS symptoms, our mildly affected twin sister may have a highly preferential expression of the EFNB1 from a single gene copy, resembling its status in hemizygosity. To our surprise, we demonstrated unequal XCl in the severely affected twin patient 5 (84\% vs. 16\%), and almost random 
$X$ inactivation in the mildly affected twin patient 6 (46\% vs. 54\%). Our finding, therefore, suggests that skewed $X$ inactivation cannot account for the mild presentation of CFNS in one of our twin sisters and probably other mildly affected female individuals. Recently, another research group did not find evidence for preferential $\mathrm{XCl}$ or a distinct correlation between $\mathrm{XCl}$ ratios in a group of familial X-linked hypohidrotic ectodermal dysplasia patients showing variable disease manifestation (21). Hence our result strengthens the above conclusion regarding the presence of additional yet undetected modifying factors resulting in discordant phenotype in X-linked disorders.

The second result of our study is the expansion of the EFNB1 gene mutational spectrum. Here, we have described three additional novel variants located in the EFNB1 gene - p.(Trp12*), p.(Tyr73Met $\left.f s^{\star} 86\right)$, p.(Glu210*) and consequently increased the total number of CFNS-associated pathogenic variants to 123 . All newly identified alterations were found applying either targeted NGS of a custom gene panel or PCR followed by Sanger sequencing. Subsequently, we evaluated the pathogenicity of the detected variants using in silico predictors (Table 2). We have also compared the phenotypic presentation of the six CFNS-affected individuals, all of whom were females (Table 1). Lastly, we have also broadened the phenotypic spectrum of CFNS syndrome, as we reported new features present in patient 3 , such as a bifid hallux, bicornuate uterus and abnormal right ovary segmented into six parts.

\section{Conclusions}

First of all, we have pointed to an unusual phenomenon of mildly affected females with CFNS, who may not manifest features suggestive of the syndrome. As a consequence, this study may be valuable for clinical geneticists consulting patients with craniofacial disorders and who potentially may overlook such individuals. Second, we excluded skewed $\mathrm{XCl}$ pattern as a cause of discordant phenotype in monozygotic twins described here. Our study strengthens the recent conclusion regarding the presence of additional yet undetected modifying factors resulting in X-linked disorders' discordant phenotype. Finally, we have expanded the mutational spectrum of the EFNB1 gene by reporting three other novel pathogenic variants causing CFNS.

\section{Methods}

\section{Targeted NGS}

We designed and applied the custom On-Demand AmpliSeq (ThermoFisher Scientific) panel targeting 37 genes related to craniofacial disorders $(9,10)$. We constructed the barcoded gDNA libraries according to the manufacturer's sample preparation protocol (Ion AmpliSeq Library Kit 2.0; On-Demand Panels) and subsequently sequenced them on the lon Torrent S5 platform using the lon $530^{\mathrm{TM}}$ or $540^{\mathrm{TM}}$ Chip.

\section{PCR and Sanger sequencing}

PCR followed by Sanger sequencing was used to validate variants detected through targeted NGS (patient 1 \& 5) and screen the coding sequence of the EFNB1 gene (patients 2-4). Besides, we performed targeted Sanger sequencing in the twin sister of patient 6 (targeted analysis of exon 4). We designed specific primers (Supplementary Table 1) using Primer3 tool v. 0.4.0. The PCR reactions and PCR product purifications were carried out following standard protocols. Next, Sanger sequencing was performed on an automated sequencer Applied Biosystems Prism 3700 DNA Analyzer using dye-terminator chemistry kit v.3, ABI 3130XL. Finally, the 
variant was visualized by applying the BioEdit tool and annotated against the reference EFNB1 sequence NM_004429.4 following the Human Genome Variation Society (HGVS) nomenclature guidelines.

\section{Zygosity test}

We used Devyser Complete v2 kit (Devyser, Sweden) following the manufacturer's protocol to analyze the twin sisters zygosity status (patient 5 \& 6). The kit contains 33 short tandem repeats (STR) markers localized on 13, $18,21, X$ and $Y$ chromosomes.

\section{$\mathrm{XCl}$ assay}

We performed $\mathrm{XCl}$ assay based on the methylation specificity of restriction enzymes at STR located within the $A R$ gene (patient $5 \& 6$ ). We used Hpall restriction endonuclease that presents a particular activity only on unmethylated gDNA. $100 \mathrm{ng}$ of gDNA was digested with either $20 \mathrm{U}$ Rsal (reference sample) or a mixture of enzymes, i.e. $20 \mathrm{U}$ Rsal and $20 \mathrm{U}$ Hpall (Thermo Fisher Scientific). After incubation and inactivation of enzymes we performed PCR amplification. The reaction was set up using FAM-labeled primers 5'TCCAGAATCTGTTCCAGAGCGTGC-3 (forward), 5'-GCTGTGAAGGTTGCTGTTCCTCAT-3 (reverse) as described by Janczar et al. (11,12). We separated the PCR products on an ABI 3130 DNA sequencing analyzer (Applied Biosystems) and analyzed in GeneMarker software v2.7.0 (SoftGenetics). The area under the peak was calculated and normalized (11).

\section{Face2Gene analysis}

We used Face2Gene tool to test whether the craniofacial symptoms present in twin patients $5 \& 6$ were characteristic of CFNS. Face2Gene's inbuilt algorithm quantifies facial gestalt based on hundreds of photographs of specific and confirmed syndrome patients. As a result, a list of possibly matching syndromes is created and ranked with a score called Gestalt Score.

\section{Abbreviations}

ACMG - American College of Medical Genetics and Genomics, CFNS - craniofrontonasal syndrome, CS craniosynostosis, NGS - next-generation sequencing, $\mathrm{XCl}-\mathrm{X}$ chromosome inactivation

\section{Declarations}

\section{Availability of data and materials}

The datasets for this article are not publicly available due to concerns regarding participants/ patients anonymity. Requests to access the datasets should be directed to the corresponding author.

\section{Ethics statement}

According to the Good Clinical Practice and Polish law, the studies involving human participants were reviewed and approved by the Bioethics Committee at Poznan University of Medical Sciences (no. 741/17 and 742/17). All patients and their parents agreed to participate in this study. Written informed consent to participate in this study was provided by the participants' legal guardian/next of kin. Written informed consent was obtained from the minor(s)' legal guardian/next of kin to publish any potentially identifiable images or data included in this article. 


\section{Authors' contributions}

A.J., A.J.-T., M.J., E.O. recruited and clinically diagnosed the patients; A.J. and E.B.-O. designed the study and wrote the manuscript; E.B.-O. performed, analyzed the molecular data and prepared figures, and tables, P.G. performed a part of in silico analysis, M.P. and M.B. participated in a part of the experimental procedures. All authors have read and approved the final manuscript.

\section{Funding}

This work was supported by the Poznan University of Medical Sciences grant - 502-14-11261860-41259 to E.B.O., the Polish National Science Centre grants 2016/23/N/NZ5/02577 to E.B.-O., 2016/22/E/NZ5/00270 to A.J.

\section{Acknowledgements}

We are grateful to the patients and their parents for participating in this study.

\section{Conflict of interest}

The authors declare that they have no conflict of interest.

\section{Web resources}

ClinVar, https://www.ncbi.nlm.nih.gov/clinvar/

Face2Gene, https://www.face2gene.com/

gnomAD, https://gnomad.broadinstitute.org/

HGMD, http://www.hgmd.cf.ac.uk/ac/index.php

OMIM, https://www.omim.org/

Primer3, http://bioinfo.ut.ee/primer3-0.4.0/

Varsome: https://varsome.com/

\section{References}

1. Cohen MMJ. Craniofrontonasal dysplasia. Birth Defects Orig Artic Ser. 1979;15(5B):85-9.

2. Twigg SRF, Matsumoto K, Kidd AMJ, Goriely A, Taylor IB, Fisher RB, et al. The origin of EFNB1 mutations in craniofrontonasal syndrome: frequent somatic mosaicism and explanation of the paucity of carrier males. Am J Hum Genet. 2006 Jun;78(6):999-1010.

3. Twigg SRF, Babbs C, van den Elzen MEP, Goriely A, Taylor S, McGowan SJ, et al. Cellular interference in craniofrontonasal syndrome: males mosaic for mutations in the X-linked EFNB1 gene are more severely affected than true hemizygotes. Hum Mol Genet. 2013 Apr;22(8):1654-62.

4. Van Den Elzen MEP, Twigg SRF, Goos JAC, Hoogeboom AJM, Van Den Ouweland AMW, Wilkie AOM, et al. Phenotypes of craniofrontonasal syndrome in patients with a pathogenic mutation in EFNB1. Eur $\mathrm{J}$ Hum Genet [Internet]. 2014;22(8):995-1001. Available from: http://dx.doi.org/10.1038/ejhg.2013.273 
5. Wieacker P, Wieland I. Clinical and genetic aspects of craniofrontonasal syndrome: Towards resolving a genetic paradox. Mol Genet Metab. 2005;86(1-2):110-6.

6. Compagni A, Logan M, Klein R, Adams RH. Control of skeletal patterning by ephrinB1-EphB interactions. Dev Cell. 2003 Aug;5(2):217-30.

7. Niethamer TK, Teng T, Franco M, Du YX, Percival CJ, Bush JO. Aberrant cell segregation in the craniofacial primordium and the emergence of facial dysmorphology in craniofrontonasal syndrome. PLoS Genet. 2020 Feb;16(2):e1008300.

8. Shotelersuk V, Kamolvisit W, Rojvachiranonda N, Suphapeetiporn K, Porntaveetus T, Shotelersuk V. Severe craniofrontonasal syndrome in a male patient mosaic for a novel nonsense mutation in EFNB1. Eur J Med Genet. 2020 Jun;63(6):103924.

9. Bukowska-Olech, Ewelina; Materna-Kiryluk, Anna; Walczak-Sztulpa, Joanna; Popiel, Delfina; Badura-Stronka, Magdalena; Koczyk, Grzegorz; Dawidziuk, Adam; Jamsheer A. Targeted next-generation sequencing in the diagnosis of facial dysostoses. Front Genet. 2020;11(November):1-12.

10. Bukowska-Olech E, Sowińska-Seidler A, Łojek F, Popiel D, Walczak-Sztulpa J, Jamsheer A. Further phenotypic delineation of the auriculocondylar syndrome type 2 with literature review. J Appl Genet [Internet]. 2020; Available from: https://doi.org/10.1007/s13353-020-00591-3

11. Janczar S, Babol-Pokora K, Jatczak-Pawlik I, Taha J, Klukowska A, Laguna P, et al. Six molecular patterns leading to hemophilia A phenotype in 18 females from Poland. Thromb Res. 2020 Sep;193:9-14.

12. Janczar S, Kosinska J, Ploski R, Pastorczak A, Wegner O, Zalewska-Szewczyk B, et al. Haemophilia A and cardiovascular morbidity in a female SHAM syndrome carrier due to skewed $\mathrm{X}$ chromosome inactivation. Eur J Med Genet [Internet]. 2016;59(1):43-7. Available from:

http://www.sciencedirect.com/science/article/pii/S1769721215300598

13. Waterhouse A, Bertoni M, Bienert S, Studer G, Tauriello G, Gumienny R, et al. SWISS-MODEL: homology modelling of protein structures and complexes. Nucleic Acids Res. 2018 Jul;46(W1):W296-303.

14. Izumi K, Hayashi D, Grochowski CM, Kubota N, Nishi E, Arakawa M, et al. Discordant clinical phenotype in monozygotic twins with Alagille syndrome: Possible influence of non-genetic factors. Am J Med Genet A. 2016 Feb;170A(2):471-5.

15. Li L, Huang L, Lin S, Luo Y, Fang Q. Discordant phenotypes in monozygotic twins with $16 \mathrm{p} 11.2$ microdeletions including the SH2B1 gene. Am J Med Genet A. 2017 Aug;173(8):2284-8.

16. Dunkerton S, Field M, Cho V, Bertram E, Whittle B, Groves A, et al. A de novo Mutation in KMT2A (MLL) in monozygotic twins with Wiedemann-Steiner syndrome. Am J Med Genet A. 2015 Sep;167A(9):2182-7.

17. Wieland I, Makarov R, Reardon W, Tinschert S, Goldenberg A, Thierry P, et al. Dissecting the molecular mechanisms in craniofrontonasal syndrome: differential mRNA expression of mutant EFNB1 and the cellular mosaic. Eur J Hum Genet. 2008 Feb;16(2):184-91.

18. Abdellaoui A, Ehli EA, Hottenga J-J, Weber Z, Mbarek H, Willemsen G, et al. CNV Concordance in 1,097 MZ Twin Pairs. Twin Res Hum Genet Off J Int Soc Twin Stud. 2015 Feb;18(1):1-12.

19. Nishioka M, Bundo M, Ueda J, Yoshikawa A, Nishimura F, Sasaki T, et al. Identification of somatic mutations in monozygotic twins discordant for psychiatric disorders. npj Schizophr [Internet]. 2018;4(1):7. Available from: https://doi.org/10.1038/s41537-018-0049-5

Page $12 / 16$ 
20. Fan X, Ping L, Sun H, Chen Y, Wang P, Liu T, et al. Whole-Exome Sequencing of Discordant Monozygotic Twin Families for Identification of Candidate Genes for Microtia-Atresia. Front Genet. 2020;11:568052.

21. Körber L, Schneider H, Fleischer N, Maier-Wohlfart S. No evidence for preferential X-chromosome inactivation as the main cause of divergent phenotypes in sisters with X-linked hypohidrotic ectodermal dysplasia.

Orphanet J Rare Dis. 2021 Feb;16(1):98.

\section{Figures}
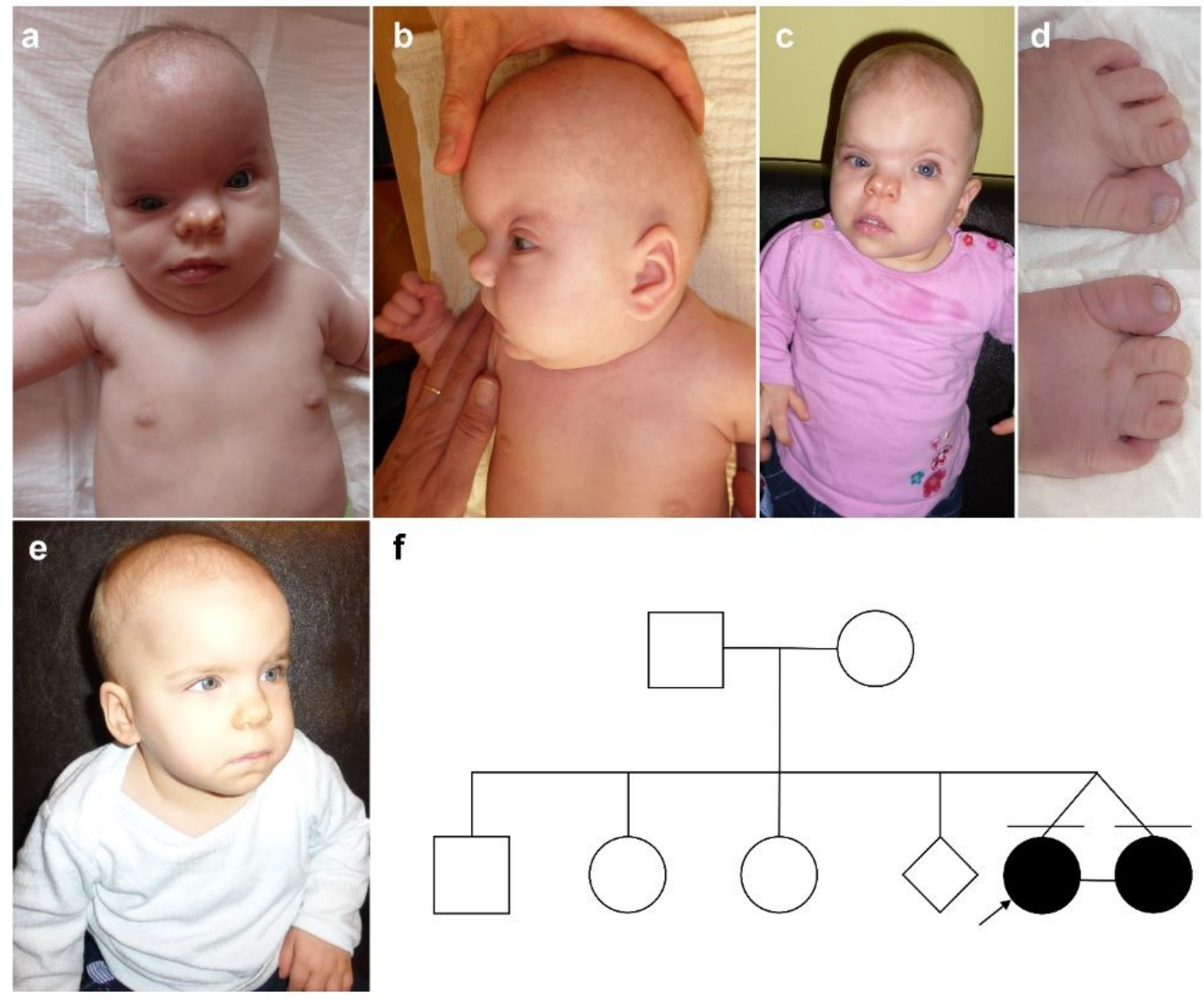

f

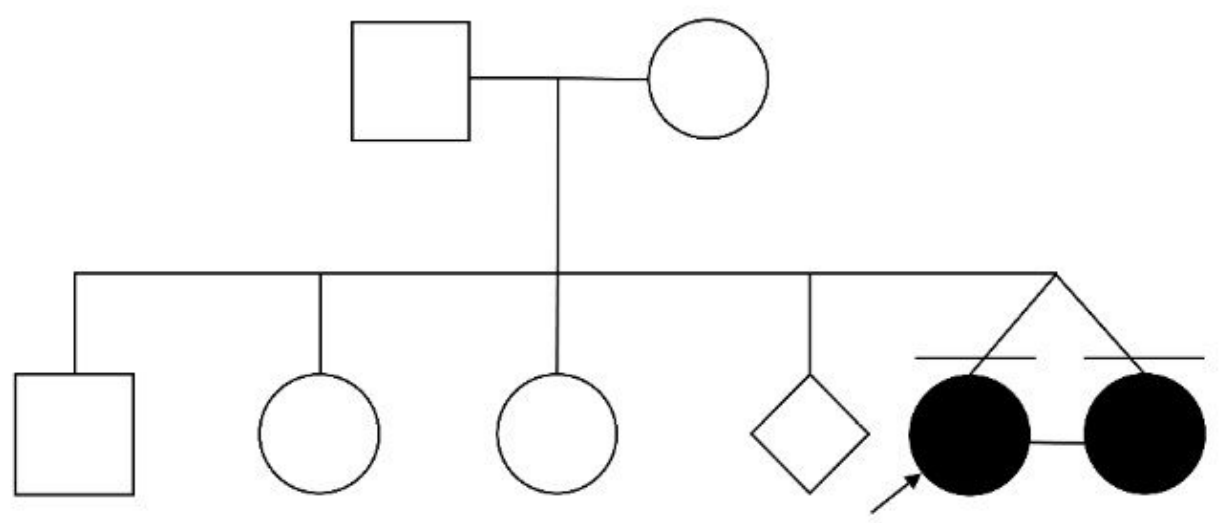

\section{Figure 1}

Patient 5 and patient 6 are monozygotic twin sisters with a highly variable clinical presentation of CFNS. While patient 5 presents with typical facial features of CFNS (a-d), patient 6 (e) shows relatively mild phenotype (see Table 1 for details) that is not suggestive for CFNS. Partial skin syndactyly of toes 3-4 of the right foot and toes 2- 
3 of the left foot diagnosed in patient $5(\mathrm{~d})$. The family pedigree (f). The analysis of relatices was not possible because twins were adopted.

a
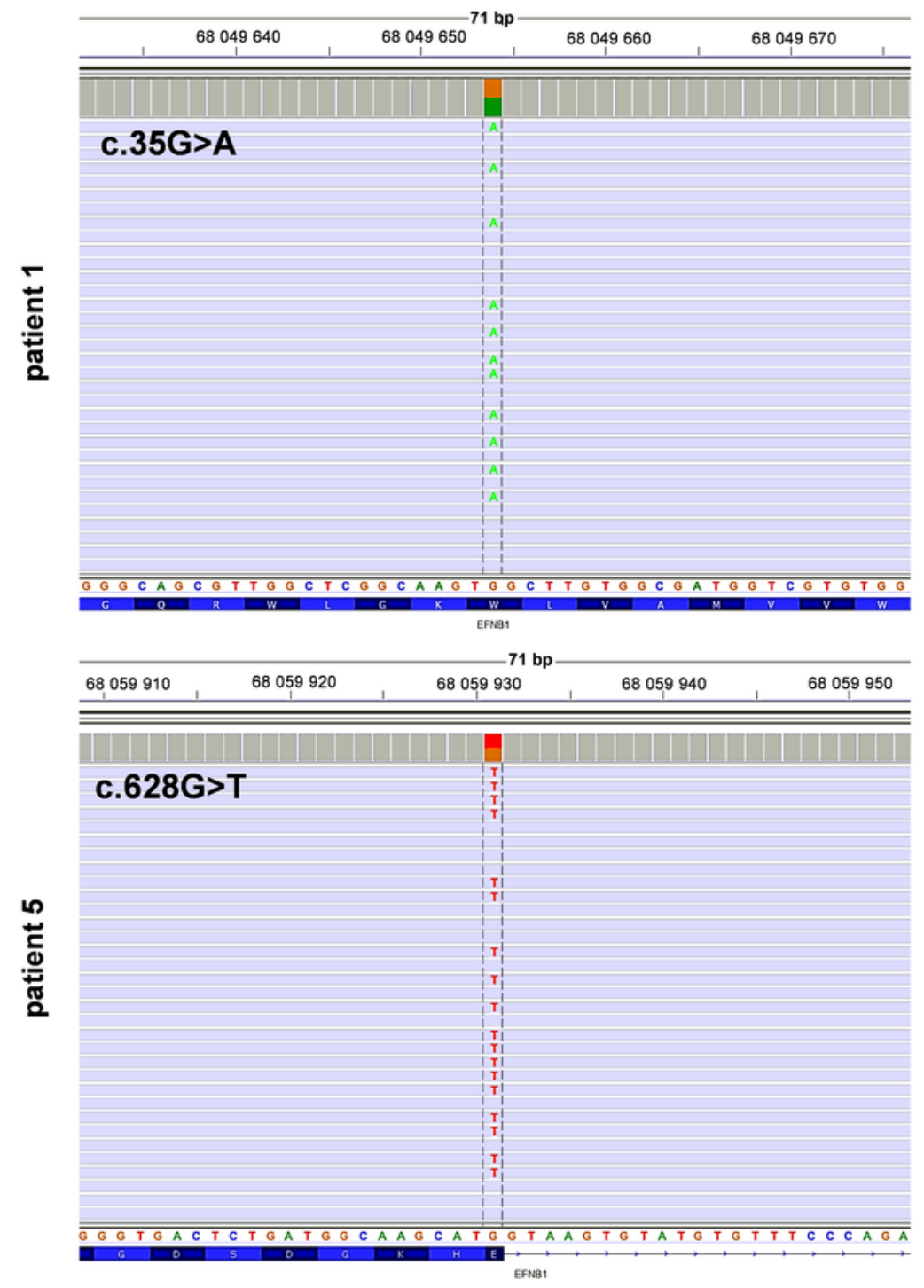

b

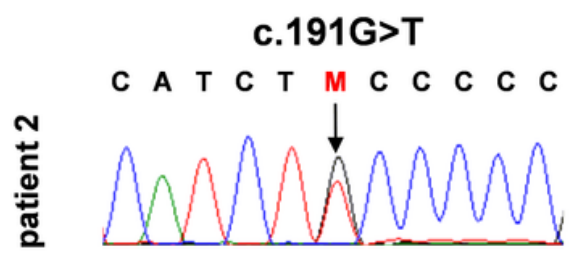

c.216delC

C G G C C M T A T G A

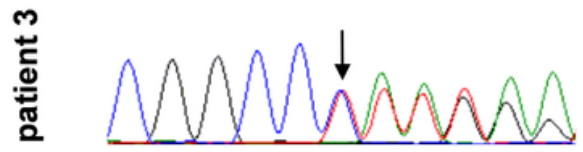

C.451G>A

A G G G C M G T G T G

壳

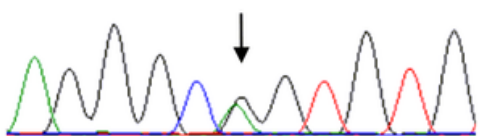

C.628G $>\mathrm{T}$

A G C A T M G T A A G

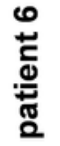

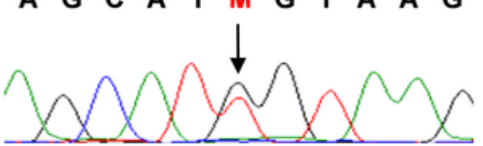

Figure 2

Targeted next-generation sequencing results (a). Pathogenic single nucleotide variants in the EFNB1 gene were visualized using Integrative Genomics Viewer (IGV) - c.35G>A p.(Trp12*) in patient 1 and c.628G >T p.(Glu210*) in patient 5. Targeted Sanger sequencing of the EFNB1 gene results (b). Pathogenic single nucleotide variants in the EFNB1 gene were visualized using BioEdit tool - c.191G>T p.(Cys64Phe) in patient 2, c.216del p. (Tyr73Metfs*86) in patient 3, c.451G>A p.(Gly151Ser) in patient 4 and c.628G>T p.(Glu210*) in patient 6. 


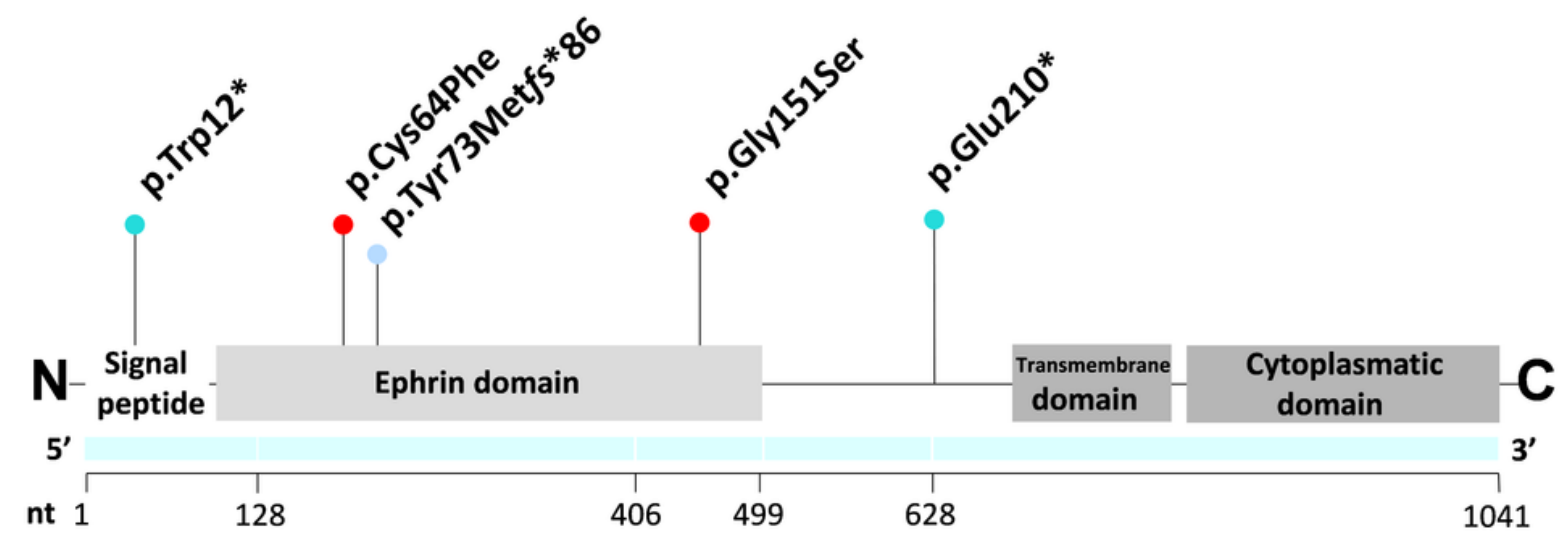

b
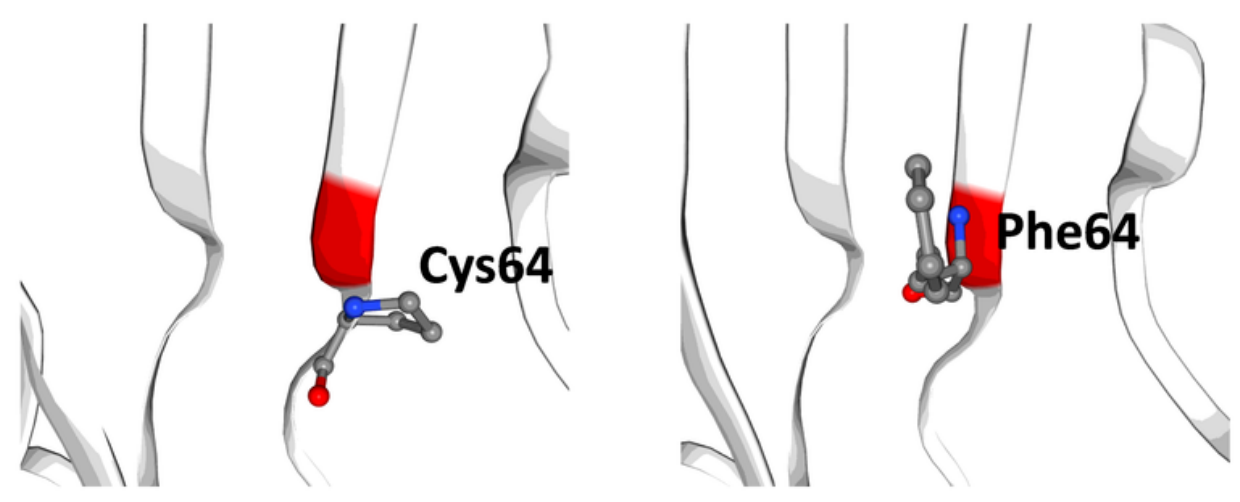

C
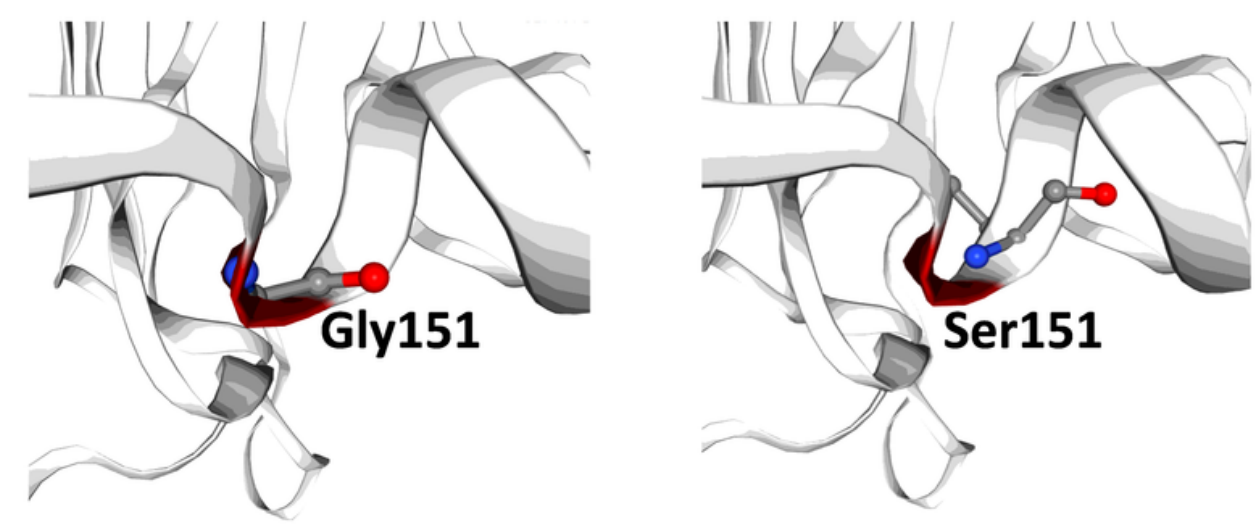

\section{Figure 3}

Schematic view of the EFNB1 gene and ephrin-B1 structure with an overview of all single nucleotide variants identified in this study (a). Ephrin-B1 is encoded by the EFNB1 gene and consists of four structural units, such as a signal peptide, ephrin, transmembrane and cytoplasmatic domains. Similarly, to our results, the great majority of all pathogenic variants occurs within the first three exons and are expected to disrupt the signal peptide and the ephrin domain of ephrin-B1. The 3D visualization of both wild type and mutated missense alterations in the ephrin-B1 made applying SWISS-MODEL, i.e. p.(Cys64Phe) and p.(Gly151Ser), i.e. p.(Cys64Phe) (b) and p. (Gly151Ser) (c).

\section{Supplementary Files}


This is a list of supplementary files associated with this preprint. Click to download.

- SupplementaryFigure131.03.2021.tif

- SupplementaryTable1.docx 